\title{
Invisibilized creativity: \\ Sociogenesis of an "innovation" process developed by cartoneros for post-consumption waste recycling
}

\author{
Sebastián Carenzo \\ Consejo Nacional de Investigaciones Científicas y Tecnológicas (CONICET), Instituto de Estudios sobre la \\ Ciencia y la Tecnología (IESCT)- Universidad Nacional de Quilmes, Buenos Aires Argentina \\ sebastian.carenzo@gmail.com
}

\begin{abstract}
Unlike the private companies that runs the waste collection system the recovery and classification of waste carried out by cartoneros (waste pickers) in Buenos Aires metropolis has not yet been acknowledged as a "public service" (one of the main demands of cartonero organizations). Their work is based on the commercialization of recovered materials for the local and global recycling industry in a market defined by high levels of intermediation and incidence of monopolies in price formation. Consequently, levels of profitability attained in this first link of the chain are extremely meager, hence the importance of achieve value-adding issues becomes key for strengthen the economies of their organizations. Moreover, some public policy actions were oriented to address this goal by a so called process of "technification" of their working process. However, the results obtained so far, were not encouraging at all. Over more than a decade of the emergence of the cartonero phenomenon in Argentina, the technological features of their job have not shown significant changes. Most of them still focus on collecting and sorting as main activities, using very rudimentary tools and machines and obtaining a small profit if we consider the hard work they make on a daily basis.
\end{abstract}

Departing from an ethnographic approach this article reconstructs and analyzes an "innovation" process developed by members of a cartonero cooperative in the Greater Buenos Aires. The project involves the recycling of industrial cellulose waste for manufacturing bricks and plates for housing construction. The core of my argument can be synthesized in the following question: what happens when an "innovation" process does not come from the contribution of specialized "technicians", but responds to an experimental practice developed by the cartoneros themselves?.

This shift at the level of the socially legitimate locus to produce "innovation" is analytically revealing for examining the contradictory dynamics in the construction of social relations deployed in this experience, focusing mainly on the tensions present in the institutionalization of the ongoing creative process.

\section{Challenging the relationship between "value addition" and "technology innovation"}

In the last years, the "value adding" issues has become a key topic in local governmental and nongovernmental agendas concerning domestic and industrial waste management, especially when analyzing the situation of the so-called "informal workers" (i.e. waste pickers who are locally known as "cartoneros") linked to these circuits. In contrast to what takes place in the current waste collection system in Buenos Aires, managed by licensed private companies, the labor of the waste pickers (collecting and sorting recyclable materials) has not yet been recognized as a "public service" ${ }^{1}$.

1 In Latin America the recognition of their work as a "public service" configures one of the main demands 
Basically, their activity is funded through selling recovered materials in a market that is basically run by chains of middlemen, in which the price formation is held by monopolies, and there is a lack of state regulations related to recyclable materials transactions (Ibañez and Corropoli, 2002). Consequently, the levels of attained profitability by waste pickers, as the first shackle of this chain, are extremely meager. Thus, the valuing of their work has become a priority in programs, projects and legislative instruments specifically designed for this population (González, 2007). However, the common aspect of this initiatives is given by a bold deterministic approach to "technology", as the main assumption is that the mere incorporation of machines into the productive process developed by waste pickers cooperatives, should have a positive impact in terms of adding value to their whole productive process ${ }^{2}$. For example, by enabling them to transform the materials they collect and sort into "inputs" to be used by larger or more complex industrial establishments (cf. Caló, 2011 for the case of glass), or to develop an "end product" to be directly commercialized (cf. Dietrich, 2011 for "molded cellulose pulp"). Nevertheless, in spite of the generalization of this deterministic discourse (particularly within policy-makers) there are still little achievements to show. More than a decade after the emergence of the "cartonero phenomena" 3 their working process, as well as the tools and machines they use, remains to be more or less the same, lacking off any kind of significant technological transformations in order to enhance their value-adding performance. With few exceptions, the majority of experiences developed by local waste pickers focus their activities on the sorting ${ }^{4}$ of collected and/or recovered materials, rather than processing $i t^{5}$. Moreover, the cooperatives that have been able to partially mechanize their working process (profiting from governmental and NGO technical and financial aid) have focused on the optimization of sorting activities. For example, by incorporating conveyor belts and presses for the bundling and stocking of classified materials (Cross, 2016). However, this does not mean that the waste pickers were not be able to develop and/or adapt technology by themselves with the intention of improving their daily work. Even when this kind of technology development has been performed in relative autonomy of

of waste picker's organizations (RedLACRE, 2016). What they have been demanding is to be hired by local governments in the same conditions of the private companies which runs the current waste collecting service. This is by bidding contracts to provide the "differentiated collection" of household's recyclable waste in each municipality jurisdiction.

2 In spite of I will only focus on waste pickers in Buenos Aires, other scholars reported similar deterministic bias over other global South countries as Brazil (Da Silva, et al. 2015), Sri Lanka (Jayasinghe and Baillie, 2015a), Egypt (Desvaux, 2014) or South Africa (Gutberlet et. at., 2016).

3 The existence of individuals and groups recovering materials and food from the waste in Buenos Aires could be considered as a longtime practice that can be traced at least back to the first decades of the $20^{\text {th }}$ century (Guillermo, 2004). However, it was only in the context of the 2001 "convertibility crisis" (Bonnet, 2003) when the massive presence of cartoneros along the streets of Buenos Aires city had became a public agenda issue. As a consequence, a harsh mass-media and legislative debate emerget to target the issue of the legality of these practices as well as their planning and regulation in the city of Buenos Aires.

$4 \quad$ Sorting activities refers to the separation of the different materials through categories (metals, plastic, cellulose, glass, etc.) and types and qualities of raw materials used in each one of them. For example, cellulose materials could be segregated into "cardboard" and "paper", but at the same time the latter involves other categories such as "white" (i.e.: photocopy paper), "second" (i.e.: magazine paper) and "newspaper", among others.

5 Transforming practices focus mainly into plastic containers and objects, because their reutilization as raw material for the manufacture of new products requires that they be previously reduced to small and uniform particles. First the material is washed and then mechanically grinded to obtain a "granulation" similar in size and shape to corn flakes. After, with an "extrusion machine" (that melts and sifts the material), homogeneous particles called "pellets" are obtained, enabling their use as input for the manufacture of new plastic containers and objects. In these cases the price of the material can rise up to $200 \%$ in relation to the price obtained for the commercialization of the raw material. 
the scientific and technological knowledge system. On the contrary, as I have stated before, they have been able to elaborate complex taxonomies of recyclable materials (Carenzo, 2016), as well as physical-chemical processes and material artifacts for its manipulation and even transformation (Carenzo, 2014). To a large extent, the legitimacy gained in these years by waste pickers organizations in the public debate on waste management as a socio-environmental issue gets closely related to the development of their unique expertise in the collecting and sorting of recyclables from the garbage. Even more, demonstrating effectiveness and efficiency in classification management as a basic practice along the circuits of recycling has been both an explicit (or tacit) requirement demanded by governmental and non-governmental agents, as well as self-imposed by the waste pickers organizations. By showing management abilities on "differential collection" programs or managing "social separation plants", ${ }^{6}$ they also try to move away the representation of their practices as exclusively attached to the "informality" paradigm (Cross, 2016; Gutberlet, 2013; Carenzo y Fernández Alvarez, 2011). In other words, they struggle to define their existence in a much more vivid and creative way, far from being a mere spasmodic "survival" reaction to their threatened life in the harsh urban environments of the current financial capitalism stage. Consequently, waste pickers were able to contest the condition of (i) legitimate actors in public and political discussion about waste management, which has been characterizing them for so long. As I will show in this paper, the waste pickers' creative action has not been directed exclusively to the search of "value addition" through material processing, but to contest the scope and role of its participation in the public debate about waste management issue. A debate that for so far had been defined in exclusively in "technoprofessional" terms ${ }^{7}$. This is, by claiming to be recognized as legitimate actors whose contributions were key to build up a wider social and environmental perspective on waste management.

My perspective draws from the work of scholars as Hess and Strobel (2013), Jayasinghe and Baillie (2015b) and Smith et. al. (2017), whose aim is to track systems of knowledge and practice oriented to problem-solving, but which move off from the hegemony of maths and science procedures ${ }^{8}$. By doing so, initiatives as the ones that I will show here, usually face prejudices and stereotype bias when trying to get recognition of their labor in terms of engineerial skills and not only as mere technical aptitudes due to the "practical" knowledge produced by the repetition of the same tasks on a daily basis. As I will try to show here, they are much more than "practitioners", as they have been developing a quite complex and creative system of knowledge and practice based on they relation to recyclable materials.

6 "Differential collection" programs establish an alternative path to what is traditionally carried out in waste management terms in the Buenos Aires metropolis, aiming to recover recyclable materials that were previously sorted by neighbours in their households. The differenciated collection could be done by waste pickers cooperatives or by private collection companies on different days and schedules. "Separation and classification plants" can be managed either by cooperatives or private companies. The main goal of this kind of devices is to minimize the waste that ends up burried in the landfill. In order to do so, the garbage truck places the waste on an elevated conveyor belt. Workers in different positions surround the conveyor belt, where each worker recovers a kind of recyclable material (plastics, paper, cardboard, glass, etc.). This process minimizes the amount of material reaching the end of the belt, that eventually is burried in the landfill.

$7 \quad$ A recent article holds that waste recycling and management is an "environmental and sanitary" topic more than a social-work topic, thus the work on the streets of "cartoneros and cirujas" was tolerated in contexts of structural crisis, but not in the current moment of sustained economic growth (Cf. Rodriguez, 2010).

8 These authors considers "ethno-engineering" as a way to track those "others ways of doing" which are often defined by what they are not (contrasting to abstract and rational codification of "western" science"), rather than what they are. By drawing on their work I could say that an operative definition of this "alternative engineering" could be defined as follows: a method of defining and solving complex issues with constanstly evolving deep experimental knowledge, highly contextual, with little utilization of modern mathematics, science or technology procedures; relying on botton-up management, practicing resoursefulness, and being contingent upon a holistic worldview (2013: 58) 
Thus, developing an ethnographic approach, this article reconstructs and analyzes the creative praxis developed by "Reciclando Sueños" (Recycling Dreams), a cooperative of waste pickers located in La Matanza (Buenos Aires) ${ }^{9}$, which includes the self-construction of machines and work tools by reusing materials recovered from waste, as well as the design of new processes for recycling those materials. I refer to praxis following Antonio Gramsci's perspective (2003), that focus in the progressive integration of action/practice and theory/thought from a perspective anchored in the experience of the popular sectors. Drawing on this, I want to stress the creative dimension of the everyday practice of waste pickers, a productive force that surpass the mere mastery of working routines by framing them into an ongoing political theory of technological action. Through this approach I propose new directions for analyzing the relationship between the production of value and the development/adaptation of technology ${ }^{10}$. Firstly, by challenging the idea that the main activity of waste pickers is restricted to collecting and sorting, but not transforming and recycling. By doing this I will highlight the importance to systematize and recognize other repertories of knowledge and skills developed by waste pickers. Secondly, in order to challenge the linear and deterministic perspective that fuels the "techno-professional" proposals for achieving value adding goals for waste pickers. Thus, the main idea is that the only possibility of valuing the waste pickers labor is restricted to the mechanization of their current work process, this is to optimize their collecting and sorting capabilities. In consequence, their subaltern position over the current value chain gets crystallized, as if the only specialization that they could achieve were only related to the classification of the different types and qualities of the recovered materials. Finally, in relation to the social locus where this experimental praxis leading to "innovations" takes place, as it does not derive from the contributions of specialized "technicians", but is elaborated from the framework of a cooperative whose members lacks off the symbolic, the economic and the technical capitals that can socially accredit these competences.

\section{The art of experimenting without capitals}

The early stages of the Recycling Dreams Cooperative of La Matanza can be traced back to 2003, when a group of former leaders of Federacion de Tierra y Vivienda (Land and Housing Federation; FTV for its initials in Spanish), ${ }^{11}$ began to organize the growing population of waste pickers in the San Alberto neighborhood. Most of them were unemployed males that began to collect recyclables from street garbage in order to make a living. This men, locally known as "cirujas" were practicing waste picking individually and had no previous experience in associative work ${ }^{12}$. Once they could gather together as

9 Covering an area of 325.71 square kilometers and with a population of 1,772,130, La Matanza is the most populated district of Greater Buenos Aires (INDEC, 2010). It also gathers a $11.9 \%$ of households with basic unsatisfied needs and the unemployment rate for 2016 was about $10 \%$ in average (INDEC, 2017).

10 Here I present preliminary results of an ongoing investigation on practices of adaptation, design and construction of technologies developed by the cooperative members, exploring a material culture approach for examining the sociogenesis of the circuits that enable the transformation of waste into merchandise. More specifically, I focus on the construction of "social forms of value" that organize and shape these circuits where discarded matter revives in social life, charged with new meanings, supporting or producing new ties and identities.

11 This organization was part of the locally so-called "piquetero" movements that played an important part during the events before and after 2001 constructing demands linked to the improvement of life conditions of the population's poorest sectors.

12 In the Metropolitan Area of Buenos Aires it is possible to account for the existence of a population historically devoted to the recovering of waste materials. These were known as "cirujas" as a derivation from the term "cirujano" (surgeon), establishing an analogy between opening up bodies and bags to draw things from the inside. For a detailed analysis of the changes in the public management of waste and recycling practices in Argentina, especially in the city of Buenos Aires, see the work of Pablo Schamber (2008). 
a cooperative, they began to improve their income, as they could join to sell a larger volume of material and negotiate better prices. As a collective they also got a kind of protection from the frequent abuse of security forces, given that since 1977 to 2006, waste picking activity was banned and repressed within the metropolitan area of Buenos Aires ${ }^{13}$. Since then, Reciclando Sueños has been actively promoting the development of waste management systems that were environmentally sustainable but also socially just, based in the collaboration between the waste pickers and the city inhabitants as part of the solution to a common problem. This approach was materialized between 2006 and 2011 when the cooperative launched an innovative waste management project called "Reciclando basura, recuperamos trabajo" (By recycling the garbage, we create our job) in local downtown centre and middle-class neighborhoods. This initiative encouraged the recyclables sorting practices in households, to be collected later by the cooperative members on a daily basis. The project provided a platform for creating the cooperative's main demand: ${ }^{14}$ to struggle for the recognition of their activity as a "public service" that must be funded under the same scheme as "traditional" waste collection, that is, with municipal resources ${ }^{15}$. In this sense, Reciclando Sueños has become reference within the waste pickers sector not only at local but regional level as well. I met the cooperative at the end of 2004, while working in an International founded "action-research" project and since then I have been working with them in a collaborative ethnography approach (Fernandez Alvarez y Carenzo, 2012). Undoubtedly, one of the attributes that fascinated me the most (and continues to do so) is related to their admirable skill for creating and dismantling household and industrial machines using all sorts of elements, tools and materials that they have been patiently collecting from trash. I still enjoy to visit the back of the cooperative's shed, where the machines for washing, grinding and drying plastics stands. There you could lose yourself within a confusing and jumbled forest of pipes, dynamos, transformers, electric engines, disassembled engine coils, roller bearings of the size of a car tires, rickety machine control panels, among other jewels that inevitably capture my attention. There is where the "fierro" (ferrous metals) is stockpiled. But certainly this does not include every piece of them. For example, the materials that later will be commercialized as metal scrap does not lay here. This privileged sector gathers only the one that has been previously "selected". This corresponds to metal things, or fragments, that embodies a certain potential to be re-used in the construction of new machines, tools and/or means of transportation, locally engineered. Thus, this category classifies (by immobilizing) this specific materials, by avoiding its circulation in the metal scrap circuit. As Webb Keane has pointed out, the materiality of objects -expressed in their durability, morphology, etcexceeds by far the conventional attributes embodied in their original manufacturing, then enabling its movement through different semiotic domains (2001: 73). From my perspective, the "seleccionado" then prefigures a key cognitive operation: the creative capacity of representing something with

13 Article 11 of the Decree-law 9,111/78 passed during the last military dictatorship, only excluded the personnel from the licensed collection service companies in each municipality, thus ensuring profitability of the service delivery. Within this context any deviation could be criminally sanctioned, motivating the intervention of public safety forces to enforce the regulation. In 2006 with the sanction of Law 13592 this decree is annulled in the province of Buenos Aires. It is noteworthy that the Cooperative Recycling Dreams along with other organizations were involved in the discussions with government officials and legislators that gave way to the definitive law.

14 Actually the recognition of their work as a "public service" has been spread through transnational networks (see Red Latinoamericana de Cartoneros y Recuperadores - RedLACRE: http://www.redrecicladores.net/) to other waste pickers organizations in Argentina and aswell at a regional level.

15 Expense derived from the delivery of this service is rated between the first and fifth place in the order of largest expenditures among the municipal public funds. The claim for recognition as a "public service" points to rederectioning part of those funds to finance experiences such as the program "Reciclando Basura, Recuperamos Trabajo". 
anticipation. But not only in the sense of being able to mentally sketch a designed, specific and so far tangible object. I'm referring to the ability of prefiguring multiple uses and re-contextualizations in a latent form, which may include potentially objectified (Miller, 1987) properties and qualities in those things or fragments. Among other examples: capacity to contain volume, rigidity to support weight, versatile shapes to be reused, etc. For example, as happened with the first working tool manufactured in the cooperative, in which the electric transformer of a discarded old commercial refrigerator was reconverted into a versatile transportable electric welding machine (see Image 1).

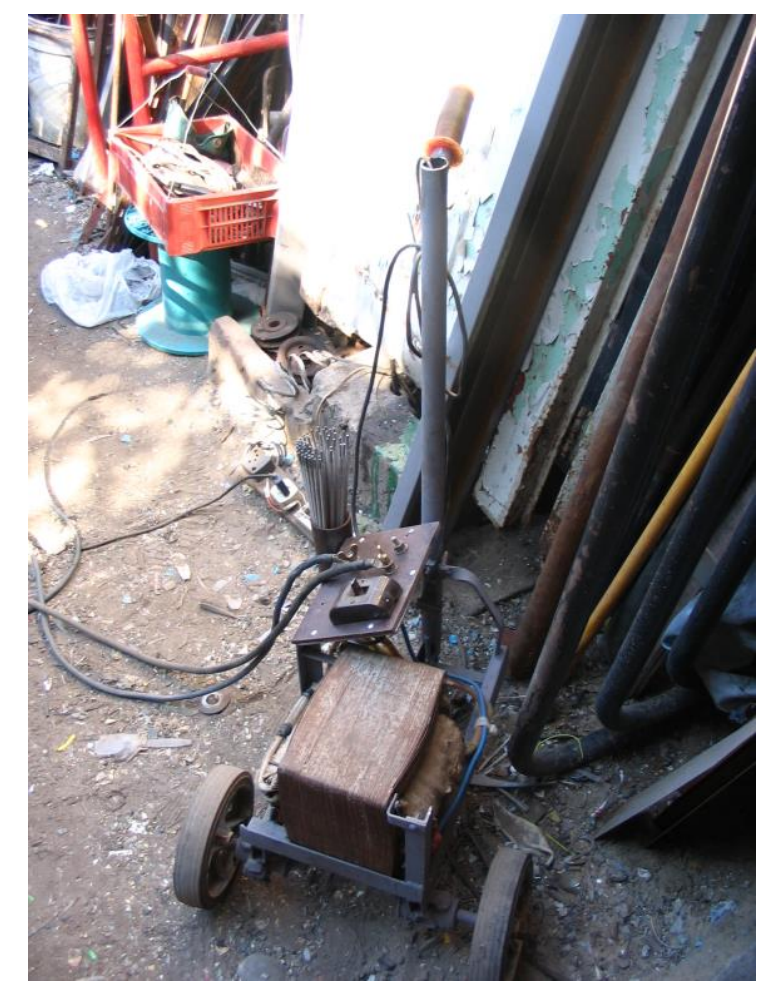

Image 1: Portable soldering iron and fragments of "selected metal"

Again, the welding machine fabricated from "seleccionado" embodied a series of deviations of different materials from the route the cooperative itself had organized to be sold generically those items as plastics recyclables and metal scrap: transformer, bicycle handle, straps and steel pipes, wheels, electric switches and wires. Instead to be commercialized as generic materials, sometime and somehow they were set apart, suspending their independent circulation and stockpiled, in a latent state until finally they got assembled under the form of a welding machine.

This is precisely what fascinates me about this set of "metals" whose apparent disorder can be misinterpreted as abandonment: the possibility of discovering them later under the rough appearance of a new machine or tool, finished or in progress. Nevertheless, not any member of the cooperative has the ability to determine what goes into the "selected" category and what does not. This skill is basically embodied in Marcelo, the Reciclando Sueños president, according to a technological trajectory forged within his own biography, as well as, a detailed knowledge of the economic circuits linked to the recycling of materials. Even though Marcelo's engineerial skills and capabilities were outstanding in comparison with most of their mates, and I will profit on that to elaborate my argument in narrative terms, it is worth to clarify that no innovation practice could have been ever achieved without the active involvement of the rest of cooperative's workers. In this sense I follow Garud and 
Karnøe (2003) advice, as I consider technological innovation as a larger process build upon the efforts of many, rather than derived from "heroic individuals" who are able to prevail by overcoming insurmountable odds. In the Reciclando Sueños case, every little achievement or failure has a collective footprint, as the creative practice is embedded in everyday working routine, challenging the capitalism labor division between making and thinking.

\section{Classification technology as organizational technology}

Marcelo is now in his fifties, and is the person in charge of the design and construction of most of the cooperative's "technological developments", as he calls them with as much pride as irony. His father developed a career as a worker in a well-known automotive factory, where Marcelo also entered when he was very young. While working there he acquired the basic notions of welding and mechanics, although in contrast to his father he was always quite the "rebel", as he describes himself, dividing his time between work in the factory and participation in left-winged political movements. At the beginning of the 90 's he was left unemployed by one of the many "personnel restructurings". He never worked in factories again, but in contrast did deepen his political activism within the "piquetero" movement, while working as a street vendor to earn a living. He remember those days as particularly "intense" due to the political, social and economical crisis whose peak corresponds to the 2001-2003 period, when the unemployment reached the $20 \%$ at a national level, but in places as La Matanza reached almost to $40 \%$ of its population (Seoane, 2002). By the end of 2003 a due to a series of conflicts, he and other five "piquetero" leaders decide to leave their active role in the organization and began to devise the project of a cooperative that aimed to gather the thousands of their own neighbors that were dedicated to waste picking as a means to survive in those deep crisis times. Owner of a restless spirit, Marcelo led the cooperative project, not only by "submerging his hands in the trash", but also by envisioning its future lines of action. At a first stage, they were dedicated to improving the basic working conditions of each member (access to carts and bags, and protection from police abuse). But at the same time, Marcelo encouraged them to develop and strengthen their sorting skills, because he realizes that it was key for valuing their work. Before then, they only sold their materials but only sorted in large categories, like paper and cardboard, PVC plastic, PET bottles, aluminum, copper and textiles.

In the following testimony, Marcelo reconstructs the process of systematization and incorporation of specific knowledge about classification:

\footnotetext{
"At the beginning we gathered all the plastic together and called it PVC. I don't know why we called it PVC. We didn't collect bags or polyethylene. Only large things and what today we call housewares, or high polyethylene or polypropylene, and at that time we called it all PVC. Because where we sold it they bought it all together and called it plastic, hard plastic. (...) Meaning, the guy that bought from us bought at the price of what was cheapest, he paid it cheaper and then separated, making two or three times more with the separation. We had to learn to separate (...) I was always a pain in the ass with some things, so I went and asked colleagues from other cooperatives that maybe knew about plastic a little more: what plastic is this one? And they said PP. And so I grabbed a marker and wrote PP and I brought it back. And this one? When I more or less had all those plastics I came back here and I told them: hey mates, this is what we have to start seeing. I saw that everybody lighted and burned the material and later we understood that materials react differently. There is one that, for example, you want to light it and it doesn't catch fire. PVC, for example, you light it and it turns into charcoal, there is no flame. OK, so if we lighted it and it didn't catch fire then it was PVC or some PVC derivative, but OK, more or less we were closer. Polyethylene smelled like candle when you lit it. The high impact one had a sort of sweet smell and releases black smoke. When you light PET it reacts like boiled plastic and things jump
} 
off and it releases a very sweetish smell, somewhat sweetish and sour, kind of strange. So you had to learn these things and we wrote it down however we could. This is how we started to seriously classify." (Marcelo interview, January $5^{\text {th }} 2005$ )

The account highlights the significance of the modest lessons learned through the relationship with middlemen (called "galponeros"), or with the owners of small and medium factories that used to buy materials to them, and even with colleagues from the other cooperatives ${ }^{16}$.

But over all, it remarks the contrast between, this self-developed sorting techniques molded under the urgency of everyday work, and the science and technology driven procedures embedded in quality standards tests, or proceedings manuals that inform the practices of the industries that feeds from by this kind of recovered materials. This is, on the one hand, the complete arsenal of "rational" and "objective" theoretical categories of modern physics and chemicals. On the other, what it's supposed to be as totally opposed, a kind of embodied procedure, based on the emotional and sensitive register of subjects. Although, it also seemed to work out in an accurate way indeed. As Marcelo's testimony shows, it was through practice that knowledge required for classification was gradually systematized and incorporated. Sometimes, by copy and imitation, as when he writes down "PP" on the object, to use it as a live model. But basically, by using their own sensitive record (sight, touch, hearing and smell) to identify materials, through a register distant from scientific procedures and categories (chemical composition) but at the same time as specific as the type of smell ("sweet", "sour") that they release when lit on fire.

Tim Ingold's critique of the technique/technology dualism (2000), offers a revealing analytical insight to take in count Marcelo's testimony. Instead of assuming the naturalized existence of the "technique" -understood as a mere practical or ad hoc skill- and the "technology" as an organized system of concepts and principles; Ingold proposes to attend to the practical dimension of the technology, in terms of an interweaving socio-technical activity. Rather than consider it as a given and finite set of knowledge and procedures subject to be replicated in a linear way, Ingold stresses the dynamic character of technology as practice, in which its interpretation cannot be separated from their specific deployment in practical contexts of activity. As Marcelo points out, the construction of classification as a technological skill is a process shaped by their job practice configuring an everyday experience. The progressive exploration and knowledge of the materiality of manipulated objects (textures, surfaces, brightness, sounds, etc) allows them to adjust the classification praxis, achieving a more efficient sorting practice, and thus better conditions to commercialize those materials. Let me now examine the conditions in which the cooperative's sorting methodology was elaborated. First of all, it's important to note that, unlike other productive activities, the recovery and sorting of recyclables from the "trash" had not count on a socially available body of knowledge, ready to be transferred by professionals, manuals, courses or internet sites, among others. In fact, this specific sorting knowledge was constructed through oral accounts from their own daily experience, reinforced by the exchange with other colleagues, middlemen and clients.

Image 2 pictures one of the posters made by Marcelo so that his mates could update references while sorting the materials previously collected from households. The poster is organized around the coding system elaborated by the Society of the Plastics Industries (SPI), that functions as a worldwide standard to be incorporated in the matrices with which plastic containers are shaped. Within this

16 Brazilian anthropologist Maria Raquel Passos Lima (2017) had also done a fine ethnography on the development of this kind of technological skills and capabilities related to sorting practices whitin the "catadores" (waste pickers) of Jardim Gramacho in Río de Janeiro. 
system the numbers ( 1 to 7 ) indicate the chemical composition of the plastic used for its manufacture, which becomes key info for its further recycling. The lower the number, the easier to recycle it.

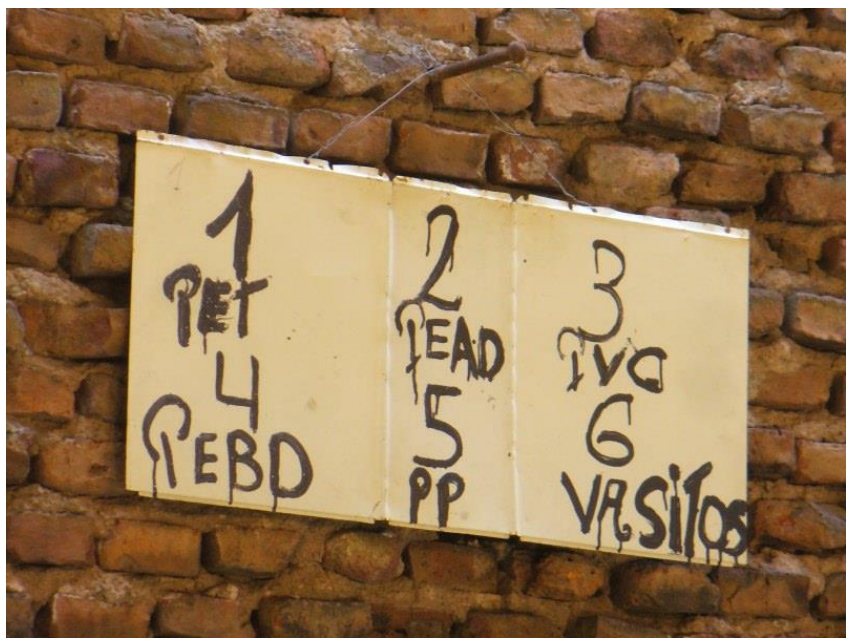

Image 2: Explanatory poster of the SPI system terminology (Photo: Mauro Oliver)

But, what it's really awesome about the poster is that operates a translation from the SPI coding to the cooperative's native categories. Some of them are analogous, like the number 1 which refers to polyethylene terephthalate or PET, a plastic widely used to manufacture containers for mass consumer goods. In particularly for soft drinks bottles, one of the most frequently objects manipulated by local waste pickers. So common they are that they refer to this kind of bottles directly as "PET". But in other categories, such as the number 6 , the native coding differs from the official one. Here is when the translation becomes more evident as it refers to a type of objects that requires a special characterization according, for example, to its frequency or the source where they collect them. In this case, number 6 corresponds to polystyrene (PE) according to the SPI coding, and to "small cups" within the cooperative's system. In fact, the "small cups" category correspond to the thermal disposable containers used in automate-vending machines to sell hot beverages, that they collect from office buildings. These disposable "small cups" were made of a material (expanded polystyrene, also called "styrofoam") that Marcelo and their mates consider it could be "recyclable in potential", even when it lacked of a regular market in where to be sold (and then, recycled) yet. At the end the expanded polystyrene was a type of plastic, so, from his point of view, it must be a way to recycle it, somehow, sometime. That is why the "small cups" were still collected, sorted and stocked, even when they could not sell them.

The "small cups" case evidence one of the limits of developing a sorting technology, or even better, the limits of depending of sorting as the principal activity they could develop as waste pickers. In this sense sorting is a practice that require lots of effort, but it provides little gains. Even more, as the "small cups" case evidence, there are many materials that even when reaches the hands of waste pickers must be discarded again due to the lack of a market in which to be sold. In the next section I propose to explore to what extent this sorting technology could be overcame. 


\section{The challenge of transcending the classification technology}

Developing a classification technology was key to structure the cooperative's functioning. It provided criteria to organize the joint work process in the warehouse where the material collected was stockpiled. It also improved commercialization conditions, as better prices were obtained when selling the pre-classified material. However, it is also important to mention that this progress was based on an enhanced integration with the existing recycling market. In other words, a market that is organized to provide recovered supplies to industrial processes developed by capitalized companies that could partially incorporate or even completely replace the use of new (and more costly) raw material. Thus, going back to Marcelo's poster, disposable bottles that account for most of category 1 materials (PET) were sold to a large Chinese collecting company that monopolizes the purchase of this material throughout the country ${ }^{17}$. Whereas category 5 materials (PP also called "bazar") mainly toys and other daily household use objects, used to be sold to two local small factories, one of which manufactured flag handles (similar to those sold at soccer stadium entrances), and the other one elaborates trophies for matches and competitions. Again, the exception was represented by category 6 "small cups", which has no buyers as there is no identifiable demand of it by the recycling industry. In fact, as it is a market-driven activity, most of the waste pickers do not collect this material nor any other that cannot be subsequently sold. So the question that emerged with urgency while doing fieldwork was: ¿why this guy is still collecting and stocking a material that has no market?

The answer is related to the analytical shifts that I have mentioned at the end of the introduction, this is, getting out of an approach that crystallizes the waste pickers as mere waste classifiers, and then, be able to track and map other creative skills that they have been developing simultaneously to their collecting and sorting job. In fact, the "small cups" had become one of Marcelo's obsessions. Not only because it was a material they cannot sold, but basically because he was simply not willing to accept that a material used to manufacture disposable instruments (cups and cutlery), could not be reused to manufacture new products. It was not only a question of money, but a far more deep analysis on the nature of the merchandise and consumerism in our current society. He repeatedly insisted that a "solution" had to be found, and thus, tried different forms of processing that material: he created blends with other types of plastic or ground it to feed a basic extruder machine. He also attempted to heat the material in order to melt it, by putting a bottled gas blow torch inside a homemade dryer machine (see image 3).

17 PET bottles are transported to Chinese industrial centers for processing to obtain synthetic yarns (e.g. fleece) that are later globally marketed. In this case the benefit came from reaching huge volumes to sell directly to this large collector which enabled obtaining a better price thanks to classification by "color" (green and crystal) and "cleanliness" (without labels or caps, that are manufactured with other types of plastic). 


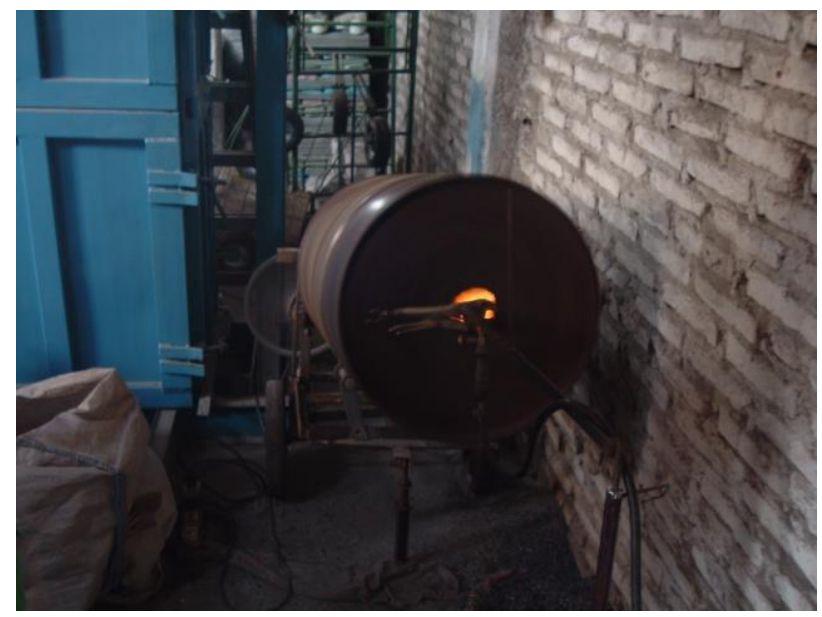

Image 3: Plastic dryer in action (Photo: Mauro Oliver)

Unfortunately, none of these attempts to transform the "small cups" worked out, even when he invested full days experimenting different types of processes, and spent a lot of time, money and energy trying to make viable their experiments. And even, using the tools, devices and resources he had at hand, that of course we're not the most adequate for the task, just like the image 3 suggests. Is precisely that practice carried out under those conditions, what I would like to highlight as a key analytical insight, because it does not really matters if his findings ended in success or failure. What is really suggestive is given by the exercise of trying to find a solution itself. This is, his attempt to make room for develop an experimental practice even when the objective conditions in which the cooperative worked may indicate the "irrational" nature of that experimental practice. Basically because this practice was conducted in a context marked by the urgency of everyday needs that usually could not be addressed considering the time and money constraints faced by the cooperative at that time. For example, Marcelo was trying to figure out how to transform the small cups while going on his way to negotiate some funding possibilities with the municipal government officers; or while he was trying to intermediate in a conflict between two cooperative's mates; or even while he was trying to fix the cooperative's 1946 Chevrolet truck as it had broken for second time in a week. Thus, it's clear that Marcelo thinks and experiments always in a "meanwhile" time, configuring basically a discontinuous and fragmentary creative process rather than a linear and continuous "organized" cognitive procedure. Far from considering it an insurmountable obstacle, or a factor to challenge the relevance or legitimacy of the whole experimental process, I would like to stress the importance of analytically addressing these actions in terms of a genuine grass-roots innovations ${ }^{18}$ initiative. Specifically, as a technological development initiative that, even when is not performed according to the science and technology standards, is much more complex that a mere trial and error procedure based on the so called "practical knowledge" basis.

Therefore it is the creative praxis developed by Marcelo and sustained by his mates what makes me think about this issue in a much more distant -and challenging- horizon than the one I have characterized before as classification technology. Because, the very core of this practice is far from only being addressed by improving their skills to manage a material for which there already was a consolidated market. For instance by refining the sorting procedures or even moving toward its processing. On the contrary, the experimental practice guided towards the "small cups" recycling,

18 As I have already mentioned, I follow the perspective traced by Smith et. al. (2017) to tackle grassroots innovation issues. 
must be understood as a process in which two main goals converge. On the one hand, to find a way to transform the plastic cups, of course. But, on the other hand, the creative and experimental process also encompasses a much more defiant goal, to "create a market" for this difficult and elusive material that forced to the limit their skills and capacities.

As a society we expect every development or novelty in the waste management field to be the result of work performed by scientific and technological centers, but not by "common" people who usually lack of the necessary social, economic and symbolic capitals to be accredited as legitimate "innovators". The shift that people as Marcelo is claiming about is related to the narrow view from which we approach to the work performed by waste pickers. Departing from an implacable economic reductionism, we assume that the creative action of individuals "in need" is inevitably anchored to material survival striving. Thus, the allocation of efforts and resources, is supposedly organized by a universal economic rationality that simply works by maximizing benefits and minimizing costs. As David Graeber points out (2001:7) the notion of value analyzed only from an economic perspective is not enough to account for the enormous amount of creative energy that people put into (apparently) unnecessary actions. In fact, this critique is constructed in reference of the classic text of anthropologist Bronislaw Malinowsky (The Argonauts of the Western Pacific, published for first time in 1922) in which the author criticizes the ethnocentric biases of western scholars when approaching to non-western economies. In this sense, and departing from utilitarian perspectives they cannot take account of the efforts and dedication of Trobrianders in growing their yam gardens, even when their productivity amply exceed their household demand. In fact, at the end, most of the produce rots and even what was actually consumed did not correspond to the growers themselves but to their extended in-laws relatives. Malinowski points out that these farmers had worked much more than necessary, since the yam gardens should not only must produce enough, but they should also had to be beautiful and attractive. Rather than minimizing effort and maximizing the profit, the author shows the importance of non-western ways of thinking about the relationship between effort and value, to make us rethink about what we have been assuming as an economic "universal" principle from our western societies.

This reflection about the Trobriand gardeners, it gets also reflected in the creative praxis carried on by Marcelo and his mates. Insofar as, the development of any practice that goes beyond of what is considered as strictly "necessary" (this is, sorting skills and stocking capabilities) is at risk of being considered as superfluous, unnecessary and even irrational by other stakeholders, specially NGO's or governmental agencies staff, which usually offers technical and financial assistance to waste pickers cooperatives. Following this line, to enhance a classification technology in waste pickers' sounds possible and rationale. In contrast, the fruitless experimental process developed around the "small cups" sounds out of place, even bragging, as it is supposed that the proper role of a waste picker in our society must be limited to collect and sort materials, but not to dream about transforming themselves into a kind of practical engineers, capable of designing new processes and artifacts. This "major" issues, which are relatively new in terms of their social elaboration, such as recycling, reusing, and as we will subsequently discuss, post consumerism, are still considered as an exclusive field for "experts".

\section{A socially dislocated "innovation" faces its limits}

Fortunately, anomalies occur from time to time. In fact, the (failed) experimentation with "small cups" was one of many attempts of that kind that I have witnessed and supported during my years working with Recycling Dreams. Just as this one in particular did not progress, others did, or rather might be on their way of doing so. In fact, the creative process leaded by Marcelo could be anything but linear. 
It recognizes a specific temporality in which discontinuity is the norm, giving rise to multiple endings and restarts. In fact, the creative process leaded by Marcelo could be anything but linear. It recognizes a specific timeline, in which discontinuity is the norm, giving rise to multiple endings and restarts. As I have stated before, this is a result of the embedded condition of the creative innovation process in the everyday realm of the cooperative. Thus, it is not developed in a task-exclusive period, on the contrary it always unfolds "while" Marcelo is doing a quite heterogeneous bunch of tasks.

Around the end of last year, Marcelo received a call from an environmental engineer who works in a multinational beer manufacturing company. "She got here by googling, through the cooperative's site", Marcelo explains to me, and he add: "She asked me if we were interested in receiving one of the industrial waste they produce, specifically the paper pulp that remains as garbage once the returnable beer bottles gets washed. And what could I say? Obviously, I said yes!". After the call, they met a couple of times at the company's manufacturing plant where, apart from the engineer, another colleague from the same section participated. In short, the situation was as follows: The paper pulp derives from bottle labels, when washed with water and caustic soda. As a result, they produce between 100 and 150 monthly tons of paper pulp, which is non-recyclable as the paper is manufactured with a fiber technique that makes it resistant to humidity. That is why labels do not tear when bottles are chilled (even if sunk in cold water). Precisely for this reason the paper recycling industry do not purchase this material from them, because it is very difficult to defiber. ${ }^{19}$ So far, this waste was being buried in the sanitary landfill, what it becomes a big issue for the company due to its costs but also to a stricter public environmental regulation related to industrial waste disposal.

Shortly after the first visit to the plant, Marcelo went into a heavily creative mood, which is expressed even in his body language: he gets very talkative while moving his hands profusely, and his forehead gets immediately covered by sweat. His first reasoning was more or less as follows: Of course the company had tried to sell this material (paper pulp), but it failed due to the characteristics of the paper used to make the labels, but also because it does not reach some procedural standards of the paper recycling industry. For example, the paper pulp waste has a small percentage of glass due to bottles that breaks in the washing process, what is "unacceptable" from the point of view of the "big players" of the recycling industry as they used to recycle only "clean" inputs. So, he figured out that may be he could explore a more eclectic way of selling it, for example, to the "galponeros" (middlemen) who could be interested in the pulp in order to mix it other kinds of paper and sell it to smaller and more versatile paper recycling factories. Given the enormous volumes at stake, even selling this material at a very low price, could guaranteed the profitability of the whole operation. In addition, the pulp not requires to be previously sorted, which also could contribute to enhance the profitability of its treatment.

Marcelo grab some of the pulp "samples" he had taken from his first visit to the plant, and began to visit some of the middlemen and small manufacturers he already known. At the very beginning, he felt very disappointed as even his closest acquaintances refused to buy the pulp by saying that it was very difficult to resell. But finally he managed to find a galponero who agreed to buy the pulp at a very low price. Everything seemed to work out, as the material began to circulate from the industry to the coop and then to the middlemen. He even managed to sign a contract with the brewery, by which the company agreed to pay the cooperative a symbolic but still significant amount: the equivalent to u\$s14 per ton to the cooperative in order to pay for the "treatment" of the pulp. Far 
from its mere economic value, the contract was key insofar as it materializes for the very first time the role of the cooperative as an "environmental service provider", in this case by treating a former "industrial waste" ${ }^{20}$ Due to the contract the cooperative received two truckloads of label pulp (over than 10 tons). Along with the trucks came the first surprises as well. The material was deposited by a dump truck in the narrow area where the classification and storage of most of the materials is made.

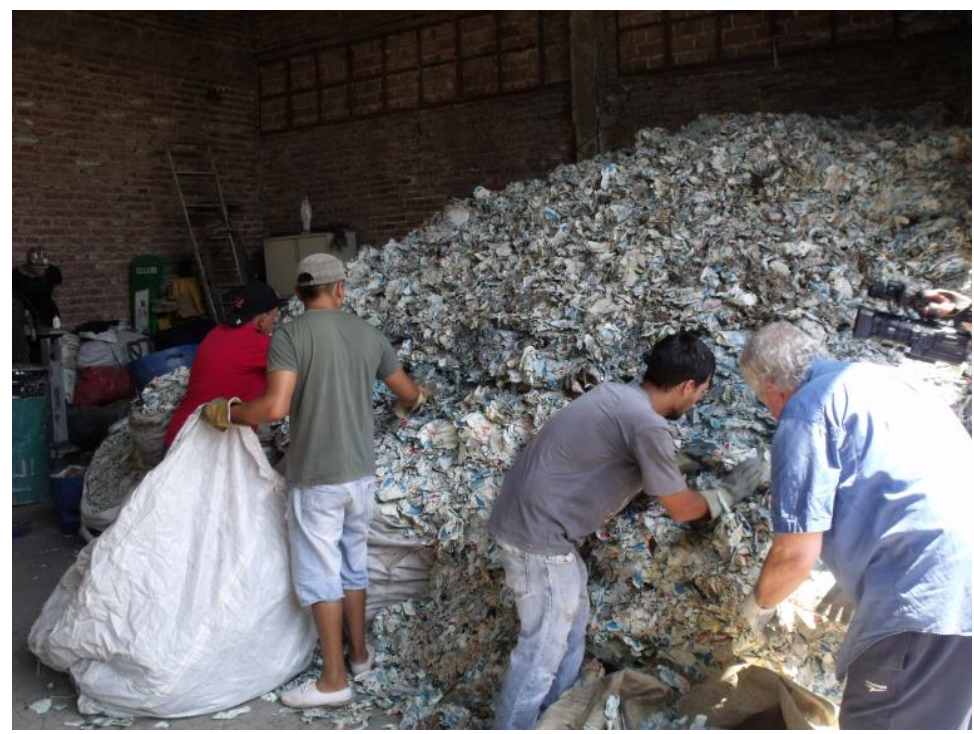

Image 4: Manipulating the label pulp after it was placed in its new location.

The sight of the pulp was shocking; it looked like an iceberg leaking from its base (the material comes with a $60 \%$ of humidity). Manipulating this material was in itself a feat; it was very compact due to the mixture of pulp, water and label glue (See image 4).Just the task of moving the iceberg from the truckload place took several days and had to be done by the collaboration of all the cooperative's crew. Due to the lack of a lift truck, it had to be manually transported: while some managed to break up the shapeless mass using pitchforks as levers, others were concentrated in pour the detached parts (twice the size of a soccer ball in average) into a big-bag type container. However, once it was full, not even eight co-workers could move it, so, they ended up handling it "one by one". This basic relocation proved to be titanic, so everyone -including Marcelo- was really worried about how they could deal with this material in a daily basis. However, complications did not end at that. After having sold only around $10 \%$ of the received material, the middlemen canceled the operation by arguing problems to sell it. The scenario had become disastrous: up to 10 tons of an unmarketable material were stacked covering the cooperative's work deck and thus, limiting the available space for stockpiling other materials. But even worse, the cancellation also damaged the possibility of meeting the terms of the "agreement" signed with the company. Very swiftly, Marcelo asked for a new meeting with the engineers in the plant. The following reconstruction corresponds to that meeting:

20 In Buenos Aires, the waste management services are provided by a couple of large private companies which basically sell the "basic" recyclables (cardboard, plastics, metals) and dump all the rest in landfills. So even when they call themselves as "enviornmental services providers", actually they are "logistics providers" as their core bussiness is much more into take and dispose industrial waste, than to explore ways of recycling. This kind of service is costly (up to 30 times the $u \$$ s14/ton of the cooperative) but also its fully organized within the environmental regulation framework. 
Once in the "meeting room", the engineer asks Marcelo about his experience with the pulp they had sent. Marcelo answers: "We cannot sell it to anybody in its actual form. It requires a process". While he was saying this he took from his bag some pieces of cardboard similar to the one pizza boxes are made of, and added: "It has to be previously defibered, the process could still be improved". Much to the surprise of the engineers, he points out: "We worked all weekend for this... if I didn't bring this samples to you, you wouldn't believe me". With the effect created by placing the cardboard on the table, Marcelo goes on by explaining his proposal. He stated that the only alternative for processing the material is first to grind it to obtain a "paste" and then pour it into frames that have to pressed until they curdle resulting in a uniform plate of varying thickness. Once this is done, it is possible to look for a certain use or to sell it as cardboard to paper companies. He repeated that the cardboard he manufactured for the meeting has a "testimonial" meaning (see image 5), and that to guarantee the feasibility of this project it is necessary to prepare a space and purchase tools and machinery (at least a powerful mill, presses, frames, and means of transportation). Finally, he closes his comments saying: "It is necessary to make a big investment, the pulp must be transformed according to a new process we are adding. If not, this is buried. Today our colleagues of the CEAMSE plants are blocking the Buen Ayre highway ${ }^{21}$ because the landfill is full. If this company can do it, it sets a good example". The engineer seems quite excited and highlighted "there is a will on both sides", but he also specifies that they have to reach a quick solution for this and adds: "We received instructions from the top to generate less and less waste. We are in hot waters, $98 \%$ of the waste is recyclable and we have to manage it well, we agree with that... but the issue of obtaining capital for this can put things off". The meeting finished with the commitment to study the proposal with the managerial level of the company. When leaving the meeting room, Marcelo approached the engineer and asked him: "Did you expected the material to be like this?" The engineer replied: "Honestly, I didn't, it is even possible to make coasters with that material. Words go by with the wind": Marcelo closes the exchange by saying. "Look, with interlocutors like you, I feel I can be very frank, that is why I am suggesting that you have to fund this...our capital is the audacity".

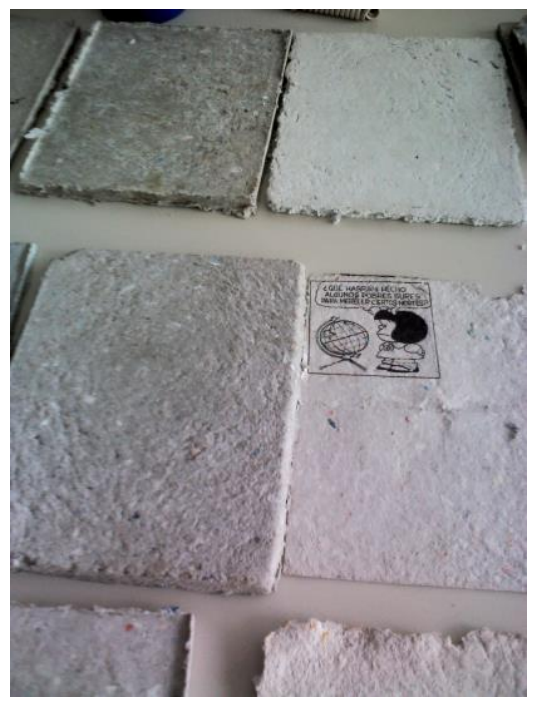

Image 5: Samples of cardboard manufactured with the pulp

21 He meant the classification plants in Complejo Ambiental Norte III, the sanitary landfill that concentrates the final disposal of the waste from the metropolitan area and where the paper pulp that the company produces is buried. 
The whole exchange, but especially Marcelo's closing phrase, brightly defines the core of the cooperative's experimental practice, as it goes far beyond the realm of what it is strictly economic nor technical. What is at stake here are definitions on how, when and by who the work of waste pickers could be socially valorized. In turn opens a broader question on which role they may assume concerning the waste management system in Buenos Aires: ¿Could a small and informal cooperative of waste pickers, become an environmental waste management services provider to a large formalized company? The answer remains inscripted in the implicit equivalence performed by Marcelo's phrase "our capital is audacity". This equivalence implies the re framing of the terms in which a multinational company negotiates with a tiny waste pickers cooperative, but at the same time, changes from top to bottom the terms of the problem that linked them together.

I'll start with the latter. The exchange between Marcelo and the engineer interrogates the terms in which the relationship has been developed so far. Basically by subtracting it from a semantics of "aid" and "collaboration", which are a common place in CSR actions when involves community-based organizations as counterparts. Marcelo's speech changes the frame of the whole relation, passing from a record based on the "lack of interest" that characterized the gift-based relations, to an exchange performed explicitly in a commercial frame, where the cooperative offers the provision of a service, for which the company must pay. The company had a "problem" (difficulty to bury the waste they produce, in the way they have been doing it so far) and the cooperative could provide an "environmental" service to facilitate the "responsible" management of waste, by means of reincorporating this waste into productive circuits based on cellulose recycling. Now, I return to the equivalence issue. The economic capital provided by the company is placed by Marcelo as equivalent to the cooperative's experimental capital, which he condenses in the term "audacity". Clearly, audacity and surprise were appropriate terms to describe the talk between coops and managers. Beyond the engineer's good intentions, perhaps Marcelo's proposal was too bold. Whilst the agreement seemed to prevent the company from sending tons of pulp to the landfill, reducing the waste management operation costs, everything seemed to be going smoothly. However, when Marcelo pointed out that to reach that goal, the company should invest some money in the cooperative in order to enhance their experimental praxis, the game changed abruptly.

At this point, I can say that this experience stresses two of the three shifts described at the beginning. First, Marcelo's audacious counter-proposal enters an area not sufficiently explored by the traditional institutions of Science and Technology: post-consumption recycling items that lacked of a consolidated market in which to be sold. Basically the bulk of waste we produce as a society has not yet been incorporated into the recycling circuits. In this sense, Marcelo's experimental practice makes us think on which are or how are defined the legitimate ways to "innovate" within the waste management field.

The samples of cardboard that he produced with the pulp are not the result of the work of academic professionals that apply theoretical principles, but to the experimental practice of "cartoneros" from a small cooperative who lack the symbolic, economic and technical capitals to socially accredit the required competences to design and develop key innovations for post-consumer waste treatment. Without this capital, no matter how appropriate and bright the innovation process might be, its possibilities of materializing in an agreement and a contract are really dim. In fact, the "agreement" with the company was canceled, and apart from the comings and goings it had during some more months, in the end no agreement was reached. The frustrated agreement with the company gave way to a new -and ongoing- experimental phase in Marcelo, based on the use of the pulp (that was of no use so far) as a "refill" for the manufacturing of construction blocks and plates. 


\section{Final reflections}

In this paper I have presented an ethnographic analysis of technological innovations related to waste management developed by local grass-roots organizations such as waste pickers cooperatives. Thus, I attempted to inquire into the objective and subjective conditions in which this creative praxis was carried out.

As a first result I deem that the main challenge we face when approaching these experiences is to be able to decenter ourselves from the account that tends to place these practices exclusively at the (quite shallow) level of the individual or collective survival. By following this line, we could easily get lost in the quicksands of economism. This is that the very aim of Marcelo and their colleagues when designing and elaborating innovations is indelibly tied to value addition as a possibility.

This bias lead us directly to two serious misunderstandings. On the one hand, to naturalize the current division of labour within the whole recycling chain, or in other words that some actors (middlemen and recycling industrials) due to their technological conditions (they have machinery, they could invest and if necessary be subjects of credit) are good to transform the materials, so they deserve to appropriate the greatest economic benefit. While other actors like the waste pickers, who lack of those technological conditions, are good to collect and sort recyclables. It seems to be like technology has little to do with these "precarious" and "informal" populations. That is why, in spite of exceptions like the cited work of Raquel Passos Lima, Caroline Baillie or Christian Luiz da Silva, there is so few scholars that ponder specifically in this sense when focusing on waste pickers.

On the other hand, as a consequence of the naturalization of the locus of the waste pickers in the first shackles of the recycling chain, we tend to evaluate their creative praxis in the narrow schema of economic rationality. This is by forcing them to translate their innovative ideas, practices and projects in terms of a strict balance between gains and losses, in which, of course, they approve with success very randomly as happens with the "small cups" or the "paper pulp".

As a result, we are invisibilizing their contribution to figure out how to deal with an ever increasing amount of garbage, not only as a working force but a deeply engaged think-tank. This is to say, the kind of people who, even when some days they lack of means to fill their family basic needs, they are thinking not only in how they could sell better the PET bottles, but to transform a material that yet could not be commercialized as such.

This does not entail celebrating irrationality; of course these machines and tools put food on the table and are useful for claiming an invisible dignity (or at least this is the intention). What I wish to highlight has to do with being (more) aware of recovering the importance of fantasy, plans, desires, everything that is seemingly useless, disproportionate o even as out of place. As a cartonero showing off his creative audacity in front of engineers that holds a university degree. Again, not to turn need into virtue, but to remind us that on some occasions these people, when shifted from where we frequently place them, force us to reflect on what is still socially (un)thinkable.

\section{References}

- Bonnet, A. 2003. La crisis de la convertibilidad. Theomai (edición electrónica), Invierno, número especial. Disponible en: redalyc.uaemex.mx/pdf/124/12490103.pdf

- Caló, J. 2011. El Agregado de Valor sobre vidrio reciclado. Ponencia presentada en Primera Jornada Nacional Gestión Integral de Residuos Sólidos Urbanos GIRSU - INTI - 28 y 29 de septiembre de 2011. 
- Carenzo, S. y M.I. Fernández Alvarez. 2011. "La promoción de cooperativas como ejercicio de gubernamentalidad: reflexiones a partir de una experiencia de cartoneros/as en la metrópolis de Buenos Aires". Argumentos, Estudios criticos de la sociedad, 24 (65): 171-198.

- Carenzo, S. 2014. "Lo que (no) cuentan las máquinas: la experiencia socio-técnica como herramienta económica (y política) en una cooperativa de "cartoneros" del Gran Buenos Aires". Antípoda, revista de Antropología y Arqueología, 18: 109-135.

- Carenzo, S. 2016), Waste Classification as a Craft under Construction: The Worker's Experience at Buenos Aires' "Social Classification Plants". The Journal of Latin American and Caribbean Anthropology, 21: 276-293-Cross, C. 2016. "Nosotros somos los que sabemos. La (re)construcción de lazos sociales en la articulación de una experiencia de trabajo asociativo en el Gran Buenos Aires". Athenea Digital, 16: 195-214.

- Da Silva, C.L; C. Rossato Bolson; C.M. Souto Ferrigotti; M. Casas Vilardell. 2015. "Tecnologia social e inclusao: Estudo de caso da Cooperativa CATAMARE". XVI Congresso Latino Iberoamericano da Gestiao da Tecnologia, Porto Alegre 19-22 Outubro.

- Desvaux, P. 2014. "Tribulations de fin de vie d'une bouteille en plastique au Caire". Géographie et cultures, 91-92: 197-211.

- Dietrich, A. 2011. El Agregado de Valor sobre Pulpa Moldeada. Ponencia presentada en Primera Jornada Nacional Gestión Integral de Residuos Sólidos Urbanos GIRSU - INTI - 28 y 29 de septiembre de 2011.

- Fernandez Alvarez, M. I. y S. Carenzo. 2012. "Ellos son los compañeros del CONICET: El vínculo con organizaciones sociales como desafío etnográfico". PUBLICAR en Antropología y Ciencias Sociales, 10 (12): 45-67.

- Garud, R. and P. Karnøe. 2003. Bricolage versus breakthrough: distributed and embedded agency in technology entrepreneurship. Research Policy, 32: 277-300

- González, H. 2007. Subprograma de Reciclado de Residuos Sólidos Urbanos. Ponencia presentada en el IV Congreso Argentino de Administración Pública. Buenos Aires 24-27 Mayo

- Graeber, D. 2001. Toward An Anthropological Theory of Value: The False Coin of Our Own Dreams. New York: Palgrave Macmillan US.

- Gramsci, A. 2003 [1958 castellano]. El materialismo histórico y la filosofía de Benedetto Croce. Nueva Visión: Buenos Aires.

- Guillermo, S. 2004. "El proceso de descarte de basura y los contextos de depositación presentes en la ciudad de Buenos Aires". Intersecciones en Antropología, 5: 25-55.

- Gutberlet, J. 2013. Social facets of solid waste: insights from the global south. Waste and Resource Management, 166: 110-113.

- Gutberlet, J.; J-H. Kain; B. Nyakinya; M. Oloko; P. Zapata and M. J. Zapata Campos. 2016. Bridging Weak Links of Solid Waste Management in Informal Settlements. The Journal of Environment \& Development, 26 (1): 106-131

- Ibáñez J.R. y Corropoli M.D. 2002. La valorización de residuos sólidos urbanos. Anuario 2002 - F.C.E. - U.N.P.S.J.B. 43

- Instituto Nacional de Estadísticas y Censos [INDEC]. 2010. Encuesta Permanente de Hogares: Mercado de trabajo, principales indicadores. Buenos Aires: INDEC.

- Instituto Nacional de Estadísticas y Censos [INDEC]. 2017. Trabajo e ingresos. Vol. 1, oo 1 Mercado de trabajo, principales indicadores (EPH). Cuarto trimestre de 2016. Buenos Aires: INDEC. - Ingold, T. 2000. The Perception of the Environment: livelihood, dwelling and skill. London: Routledge. - Jayasinghe, R. and C. Baillie. 2015a. Engineering with people: a participatory needs and feasibility study. In: Jayasinghe, R. and C. Baillie (Eds.) Green Composites: Waste and Nature-based Materials for a Sustainable Future. Duxford: Woodhead- Elsevier.

- Jayasinghe, R. and C. Baillie. 2015b. Making visible the invisible: Exploring the informal wastescape in the Western province of Sri Lanka. Geoforum. 
- Keane, W. 2001. Money is no object: Materiality, desire and modernity in Indonesian society. In: Myers Fred (Ed.). The Empire of Things: Regimes of Value and Material Culture. Santa Fe: School of American Research Press. p. 65-90.

- Miller, D. 1987. Material culture and mass consumption. Oxford: Blackwell.

- Passos Lima, M.R. 2017. Plasticidades recriadas: conhecimento sensível, valor e indeterminação na atividade dos catadores de recicláveis. Sociol. Antropol. 7 (1): 209-238.

- RedLACRE. 2016. Políticas Red Latinoamericana y del Caribe de Recicladores. Secretaría General Intinerante. Consultado el 15-12-2016. Disponible en: http://www.redrecicladores.net/wpcontent/uploads/2016/10/POLITICAS-RED-LACRE.pdf.

- Rodriguez, C. 2010. Gestión Integral de Residuos, Reciclado y Cartoneo en Buenos Aires. Buenos Aires: Editorial Croquis. 190 pp

- Schamber, P. 2008. De los desechos a las mercancías: Una etnografía de los cartoneros. Buenos Aires: SB.

- Seoane, J. 2002. Argentina: la configuración de las disputas sociales ante la crisis. Revista del Observatorio Social de América Latina, 7: 37-43.

- Smith, A.; M. Fressoli; D. Abrol; E. Arond; A. Ely. 2017. Grassroots Innovation Movements (Pathways to Sustainability). London: Routledge. 